Note

\title{
Morphological, behavioral and biological aspects of Azya luteipes Mulsant fed on Coccus viridis (Green)
}

\author{
Juliana Nais ${ }^{1}$, Antonio Carlos Busoli*
}

1UNESP/FCAV - Programa de Pós-Graduação em Entomologia Agrícola.

2UNESP/FCAV - Depto. de Fitossanidade - Via de Acesso Prof. Paulo Donato Castellane, s/n. - 14884-900 -

Jaboticabal, SP - Brasil.

*Corresponding author <acbusoli@fcav.unesp.br>

Edited by: Luís Reynaldo Ferracciú Alleoni
ABSTRACT: One of the major pests of nursery seedlings of coffee (Coffea arabica L.) is the green scale, Coccus viridis (Green) (Hemiptera: Coccidae). The main predators of this species are beetles of the family Coccinellidae, especially Azya luteipes Mulsant. Morphological, behavioral and biological aspects of $A$. luteipes feeding on $C$. viridis on coffee plants were examined under laboratory conditions. Tests were conducted in room temperature at $28 \pm$ $2{ }^{\circ} \mathrm{C}$. A. luteipes oviposits on the underside of the scale's body, laying two to four eggs per insect. The eggs have a subelliptical form and a white-clear color, and the incubation period is $8.3 \pm 1.2$ days. The number of eggs laid per female per day varies between eight and ten. A. luteipes undergoes four larval instars with durations of $2.0 \pm 0,3.2 \pm 0.5,3.6 \pm 0.5$ and $4.6 \pm 0$ days for the $1^{\text {st }}, 2^{\text {nd }}, 3^{\text {rd }}$ and $4^{\text {th }}$ instars, respectively. The average durations of the prepupal and pupal stages were $2.0 \pm 0$ and $10.9 \pm 1.3$ days, respectively. The viability of the larvae during each instar was $91.9,89.3,90.2$ and $96.4 \%$, respectively, and the viabilities of prepupae and pupae were 99.1 and $98.2 \%$. The average duration of the egg-adult cycle was $34.3 \pm 2.6$ days, and the sex ratio was $0.52 \%$. Females presented a gray-colored head, while males presented a yellow head.

Keywords: coccinelids, green scale, development, oviposition behavior, life cycle

Received August 23, 2010

Introduction

Brazil has a strong tradition of coffee /Coffea arabica L.) cultivation, and one factor that can reduce the productivity and quality of coffee plants is the attack of insect pests. Among the major coffee pests are scale insects of the families Coccidae, Pseudococcidae and Diaspididae. Attack by these insects involves attachment, followed by piercing of the coffee plant leaves with the insect's mouth apparatus and sucking of the sap, which also involves the introduction of toxins that cause leaf drop and reduce productivity and fruit quality (Bartra, 1974).

The green scale, Coccus viridis (Green) (Hemiptera: Coccidae), is usually found on coffee new branches and leaves, especially along the midrib of the leaves (Dekle and Fasulo, 2001). The biological control of this scale insect primarily involves several natural enemies, mainly species of Coccinellidae (also known as ladybugs), which in both their larval and adult phases are voracious predators (Hagen, 1962; Clausen, 1972).

Among the various species of ladybugs are those belonging to the genus Azya Mulsant, which includes 13 Neotropical species, most of which have potential value for biological control (Almeida and Carvalho, 1996). The ladybug Azya luteipes Mulsant (Coleoptera: Coccinellidae) is widely cited as a predator of many scale insect species of the family Coccidae (Bartlett, 1978). Regarding the behavior of Coccinellidae species in general, ladybugs employ multiple defense mechanisms against their predators, like thanatosis (dropping to the ground and feigning death) (Daloze et al., 1995).
Although $A$. luteipes is well-known in scientific citations, publications about its biology and morphology are scarce in the scientific literature. Considering that $A$. luteipes has great potential as a biological control agent, the objective of this study was to observe the life cycle of this species when fed on $C$. viridis under laboratory conditions and to record aspects of its morphology and behavior.

\section{Materials and Methods}

Sweet orange [Citrus sinensis (L.) Osbeck] leaves infested with $C$. viridis were collected in Jaboticabal, State of

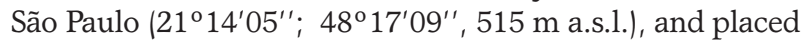
on leaves of $C$. arabica L. (cv. Mundo Novo) seedlings, allowing movement of green scale nymphs from detached citrus leaves to the coffee seedlings. Thirty coffee seedlings ranging from three to six months in age, and from 40 to 60 $\mathrm{cm}$ in height, were planted in plastic bags and maintained in a greenhouse with appropriate cultural practices.

The initial specimens of the ladybug $A$. luteipes were adults and larvae collected with the help of an entomological suction tube from Citrus sinensis cv. Pêra plants and transferred to the coffee seedlings infested with green scale. The mass rearing of $A$. luteipes in the laboratory occurred in round plastic containers of about $15 \mathrm{~cm}$ in height and $10 \mathrm{~cm}$ in diameter with small holes in the lids to allow gas exchange. Cages had two vents on opposite sides from each other and were lined with voile fabric and capped with $0.5-\mathrm{cm}$-thick clear glass. Cages sat on a layer of foam for sealing and containment of the insects (Silva et al., 2003). Insects were maintained at a room 
temperature of $28 \pm 2{ }^{\circ} \mathrm{C}, 70 \pm 10 \%$ relative humidity and a 12-h photophase.

Eggs were transferred, with the help of small brushes, to separate individual polyethylene cages $160 \mathrm{~mm}$ in diameter and $20 \mathrm{~mm}$ in height) for observation of the incubation period. The immature forms of the ladybugs reared in each plastic container were observed daily to detect exuviae and instar transitions. From this laboratory rearing, adults were used to study the following biological parameters: pre-oviposition period; number of eggs per female per day; number, duration and viability of larval instars; and sex ratio. Both larvae and adults were reared on coffee leaves infested with 80 to 100 adult scale insects and hundreds of nymphs. Leaves were changed daily until the completion of the predator's life cycle to ensure an abundant supply of prey. The adults were offered a food supplement comprised of a $10 \%$ honey solution in a small container with a cotton swab at the bottom of the cage.

About 35 mating pairs were selected from among the newly emerged adults. Eleven mating pairs were placed in individual plastic containers and the remaining pairs were arranged in the cages described above. Two newly emerged mating pairs were placed in each cage on a coffee plant infested with green scale adults and nymphs. A $10 \%$ honey solution was offered as a food supplement, and the cages were maintained at a temperature of $28 \pm 2{ }^{\circ} \mathrm{C}$. Coffee plants were inspected daily under a stereoscopic microscope to observe the oviposition behavior of females (i.e., the location and quantity of eggs laid). The gender of the adults was determined based on detailed observations of the morphological characteristics of males and females. Larvae and adults were also kept together to observe cannibalistic behavior. The viability of each larval instar, the durations of the prepupal and pupal periods, the duration of the egg-adult cycle and the percentages of viability for each stage of the ladybugs' development were also calculated.

\section{Results and Discussion}

The female ladybug lays her eggs under the body of an adult green scale, lifting the edge of the scale's shell to deposit the eggs under the body of the insect, which then may be completely or partially consumed (Figure 1a). Oviposition beneath the bodies of scale insects protects the eggs of the coccinellid from natural enemies, ensuring hatching of the larvae. Similar oviposition behavior has also been observed in the ladybugs Azya bioculata Gordon (Ricci, 1985), in Coccidophilus citricola Brèthes (Silva et al., 2003, 2004) and in Pentilia egena Mulsant using the oleander scale, Aspidiotus nerii Bouche (Guerreiro et al., 2003). We rarely observed oviposition directly on the plants, noting only a few eggs in the axillae of the leaf petioles, in small holes and crevices of new stems and on leaves still attached to new shoots. We found no eggs on the walls of the recipient cages containing the insects and plants.

The number of eggs oviposited under the body of an adult green scale usually varies from two to four, but may be as many as seven. The number of eggs per female per day varies from eight to ten, reaching as many as twenty, depending on the age and longevity of the mating pair. Silva et al. (2005) have reported similar numbers of eggs of $C$. citricola under the body of the diaspidid $A$. nerii. Eggs were very fragile and had a subelliptical shape and a white-clear color (Figure 1b). The average incubation period is $8.3 \pm 1.2$ days. A. luteipes exhibited four larval stadium, confirming the observations of Hodek (1973) for coccinellids in general. The average duration of each stadium was $2.0 \pm 0,3.2 \pm$ $0.5,3.6 \pm 0.5$ and $4.6 \pm 0$ days for the $1^{\text {st }}, 2^{\text {nd }}, 3^{\text {rd }}$ and $4^{\text {th }}$ instars, respectively. The larvae are agile and of the campodeiform type, with a yellowish color and a covering of white waxy filaments (Figure 1c). This covering protects the larvae against opportunistic attacks from generalist predators, such as ants and birds. When disturbed, the larvae produced yellowish droplets, apparently odorless and slightly sticky, from joints under the thorax, especially in the coxal cavity. These substances probably correspond to the predator-repelling alkaloids reported by Daloze et al. (1995), which are produced by most species of Coccinellidae. In Adalia decempunctata L. and A. bipunctata (L.), Lognay et al. (1996) have identified a piperidine alkaloid in the defensive secretions. Moreover, Lebrun et al. (1997) have found the substance 2-dehydrococcinelline to be a defensive alkaloid excreted from various parts of the body of the coccinellid Anatis ocellata L..

During each ecdysis, the larva abandons the exuviae and seeks to hide, probably to begin production of the waxy extensions of its body, which may be seen after about $24 \mathrm{~h}$ on the dorsal surface of the larva (Figure $1 \mathrm{~d}$ ). As the pupal phase approaches, the fourth instar larvae go through a period called prepupal phase (Hodek, 1973), during which feeding is interrupted and the larvae remain motionless. The production of waxy filaments increases during this time, making the larvae appear to have increased volume.

In the pupal phase, the insect's body remains covered by the last exuviae and, above that, a large quantity of waxy filaments (Figure 1e). The average durations of the prepupal and the pupal phase were observed to be $2.0 \pm 0$ and $10.9 \pm 1.3$ days, respectively. The viability of each larval stadium was $91.9,89.3,90.1$ and $96.4 \%$, for the $1^{\text {st }}, 2^{\text {nd }}$, $3^{\text {rd }}$ and $4^{\text {th }}$ instars, respectively, and 99.1 and $98.2 \%$, for the prepupal and pupal phases, respectively. The total average duration of the egg-adult cycle was $34.3 \pm 2.6$ days, and the total viability across the life cycle was $79.4 \%$. When up to four larvae were kept together in a single container without food, no cannibalism was observed.

When touched, adult $A$. luteipes retract their antennae and legs and fall to the ground as if dead, as observed by Costa Lima (1953) for the majority of coccinellids. This behavior, called thanatosis, is a defense mechanism against predators (Daloze et al., 1995). The sex ratio observed in the experiment was 0.52 , meaning that $52 \%$ of the emerged adults were females (Figures $1 \mathrm{f}$ and $1 \mathrm{~g})$. The sex of adults can be easily distinguished by 

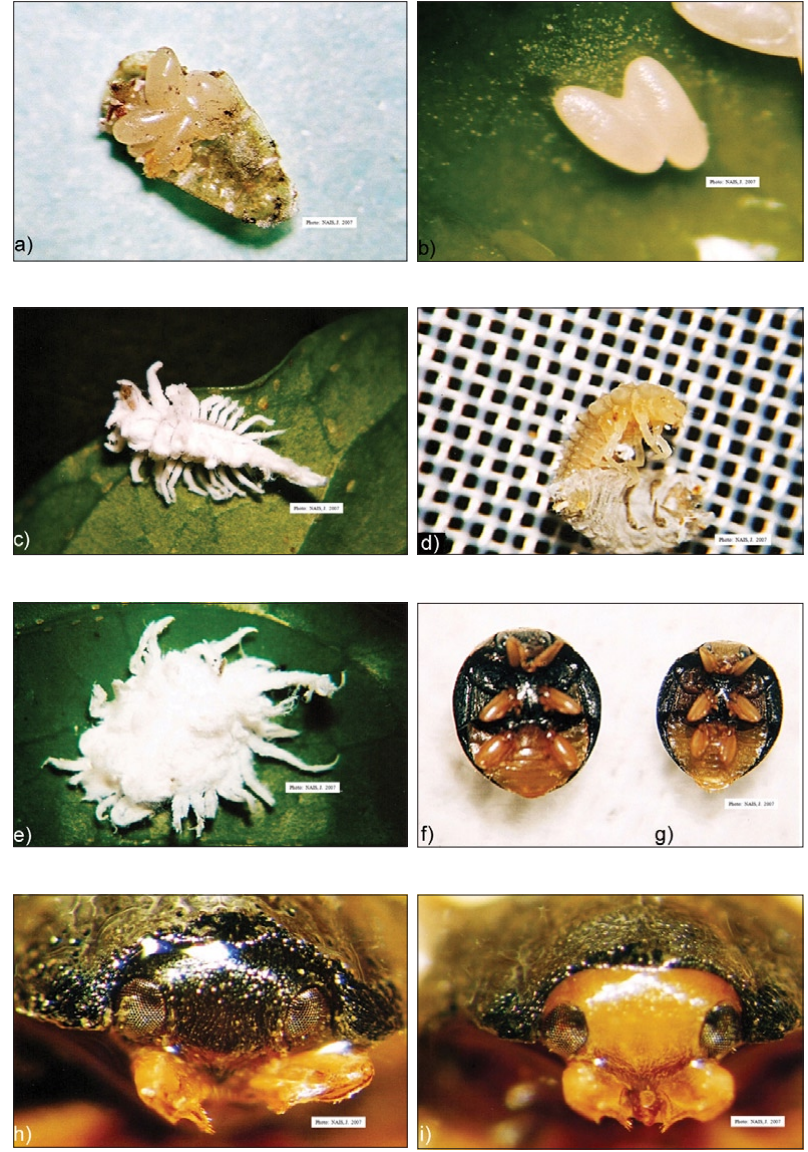

Figure 1 - Photographs of A. luteipes: a - Oviposition in the ventral region of the green scale's body (16X). b - Eggs (detail, 20X). cLarva of $4^{\text {th }}$ instar (12X). d- Ecdysis of larva of $2^{\text {nd }}$ instar (12X). e- Pupa (10X). f-g - Adult: f- female. g- Male (18X). h-i- Detail of the head coloration: female (h) and male (i) (20X).

their head coloration. Females have a gray head, the same color as the elytra (Figure $1 \mathrm{~h}$ ), while males have a yellowish head (Figure 1i). When mating pairs were confined to coffee plants with low densities of prey due to previous predation pressure, the adults partially preyed upon their own eggs, demonstrating a form of cannibalism.

\section{Acknowledgements}

To Conselho Nacional de Desenvolvimento Científico e Tecnológico ( $\mathrm{CNPq})$, for the scholarship awarded to the first author.

\section{References}

Almeida, L.M.; Carvalho, R.C.Z. 1996. A new species of Azya Mulsant from Brazil (Coleoptera, Coccinellidae) feeding on Pulvinaria paranaensis Hempel (Homoptera, Coccidae) in Ilex paraguariensis st.hil. (Aquifoliaceae). Revista Brasileira de Zoologia 13: 643-645.
Bartlett, B.R. 1978. Coccidae. p. 57-74. In: Clausen, C.P., ed.. Introduced parasites and predators of arthropod pests and weeds: a world review. USDA/ARS, Washington, DC, USA. (Handbook, 480).

Bartra, P.C.E. 1974. Biology of Selenaspidus articulatus Morgan and its main biological control. Revista Peruana de Entomologia 17: 60-68 (in Spanish).

Clausen, C.P. 1972. Entomophagous Insects. Hafner, London, UK.

Costa Lima, A. 1953. Insects from Brazil: Coleoptera: 2nd Part. Escola Nacional de Agronomia, Rio de Janeiro, RJ, Brazil (in Portuguese).

Daloze, D.; Braekman, J.C.; Pasteels, J.M. 1995. Ladybird defence alkaloids: structural, chemotaxonomic and biosynthetic aspects (Coleoptera: Coccinellidae). Chemoecology 6: 173183.

Dekle, G.W.; Fasulo, T.R. 2001. Featured Creatures: "Green Scale". University of Florida, Gainesville, FL, USA. (DPI Entomology Circular, 165).

Guerreiro, J.C.; Busoli, A.C.; Berti Filho, E. 2003. Oviposition and predation of Pentilia egena Mulsant (Coleoptera: Coccinellidae) in response to temperature. Scientia Agricola 60: 587-589.

Hagen, K.S. 1962. Biology and ecology of predaceous Coccinellidae. Annual Review of Entomology 7: 289-326.

Hodek, I. 1973. Biology of Coccinellidae. Academics of Science, Prague, CZ.

Lebrun, B.; Braekman, J.C.; Daloze, D.; Pasteels, J.M. 1997. 2-dehydrococcinelline, a new defensive alkaloid from the ladybird beetle Anatis ocellata (Coccinellidae). Journal of Natural Products 60: 1148-1149.

Lognay, G.; Hemptine, L.; Chan, F.Y.; Gaspar, C.; Pasteels, J.M. 1996. Adalinine, a new piperidine alkaloid from ladybird beetles Adalia bipunctata and Adalia decempunctata. Journal of Natural Products 59: 510-511.

Ricci, J.G. 1985. Comparative morphology, biological data and predator habit of Hyperaspis brethesi n.sp., Azya bioculata Gordon (Col., Coccinellidae) and Pycnocephalus argentinus Brèthes (Col., Nitidulidae), predators of Coccus perlatus (Cockerell) (Hom., Coccoidea) in citrus in Tucuman (Argentina). Revista de Investigación CIRPON 3: 53-70 (in Spanish, with abstract in English).

Silva, R.A.; Guerreiro, J.C.; Michelotto, M.D.; Busoli, A.C. 2003. Development and predatory behavior from Coccidophilus citricola Brèthes, 1905 (Coleoptera: Coccinellidae) on Aspidiotus nerii Bouché, 1833 (Hemiptera: Diaspididae). Boletín de Sanidad Vegetal Plagas 29: 9-15 (in Portuguese).

Silva, R.A.; Busoli, A.C.; Chagas-Filho, N.R. 2004. Biological aspects of Coccidiphilus citricola Brèthes 1905 (Coleoptera:Coccinellidae). Ciência Rural 34: 667-672 (in Portuguese, with abstract in English).

Silva, R.A.; Almeida, L.M.; Busoli, A.C. 2005. Morphology of immatures and adults of Coccidophilus citricola Brethes (Coleoptera: Coccinellidae: Sticholotidinae), predator of scales-of-shell (Hemiptera: Diaspididae) of citrus. Revista Brasileira de Entomologia 49: 29-35 (in Portuguese, with abstract in English). 